\title{
Extracranial internal carotid artery aneurysm coexisting with multiple intracranial arteriovenous malformations
}

\author{
Multipl intrakraniyal arteriyovenöz malformasyonlar ile birliktelik gösteren \\ ekstrakraniyal internal karotis arter anevrizması

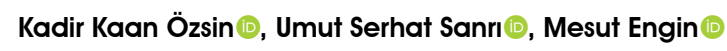

Department of Cardiovascular Surgery, University of Health Sciences, Bursa Yüksek Ihtisas Training and Research Hospital, Bursa, Turkey

A 54-year-old female patient was admitted to our outpatient clinic with a pulsatile mass and pain in the right side of her neck. Carotid Doppler ultrasonography revealed an aneurysm of the right internal carotid artery (ICA). Carotid artery angiography showed a right ICA aneurysm, measuring $3 \times 2 \mathrm{~cm}$ (Figure 1). Before surgery, multidetector computed tomography (MDCT) was performed to demonstrate the aneurysmal arterial segment and its connections with normal arterial structures. Multidetector computed tomography demonstrated multiple fusiform aneurysmal segments of both intracranial and extracranial carotid arteries, and aneurysms associated with arteriovenous malformations (AVMs) within the zone of circle of Willis (Figure 2). The patient was transferred to
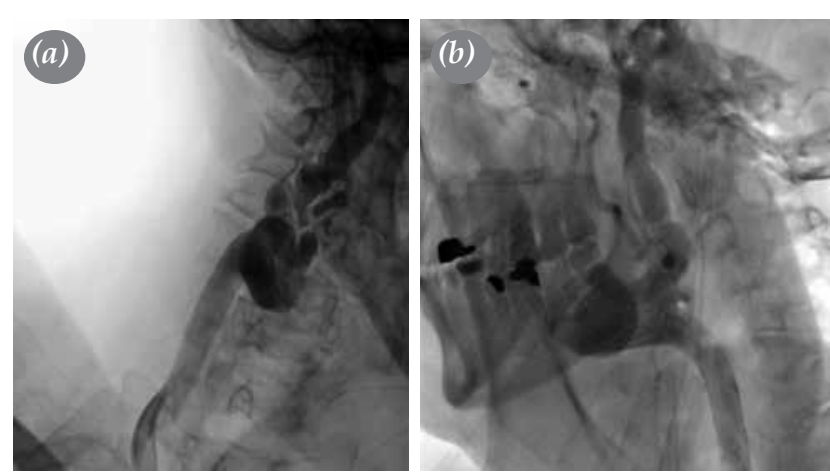

Figure 1. Conventional carotid angiography images of (a) right and (b) left carotid arteries. another hospital for further evaluation of definitive diagnosis and treatment.

Extracranial ICA aneurysms are rare and have an incidence of about $0.8 \%$ among all arterial aneurysms. Pathology may include; local infection, atherosclerotic disease, dissection, and previous carotid artery surgery. ${ }^{[1]}$ Catastrophic outcomes may be encountered, such as hemorrhage and stroke. ${ }^{[2]}$ Therefore, aneurysms should be treated. Treatment
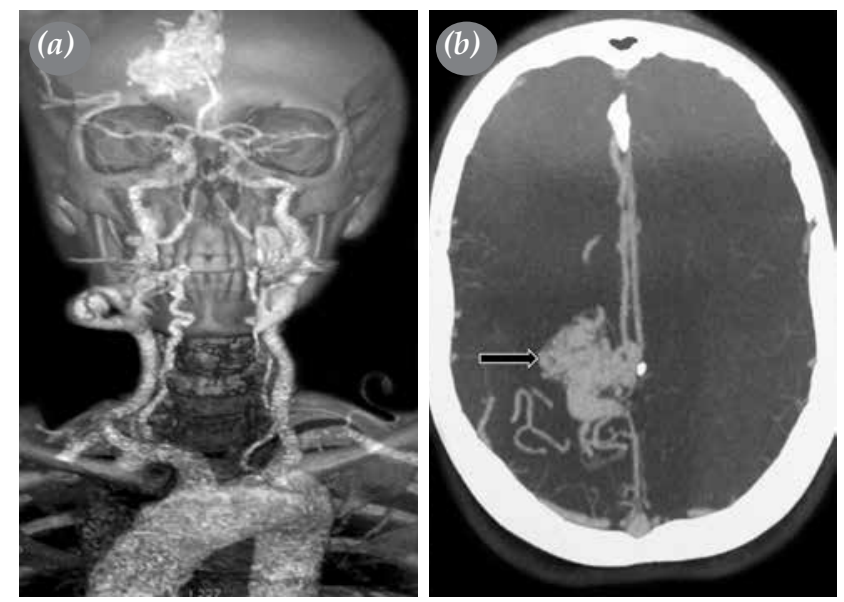

Figure 2. (a) Multidetector computed tomography images demonstrate extracanial and intracranial carotid artery aneurysms with intracranial arteriovenous malformations. (b) Cranial multidetector computed tomography image of intracranial arteriovenous malformations.

Received: January 23, 2017 Accepted: March 29, 2018

Correspondence: Mesut Engin, MD. Sağlık Bilimleri Üniversitesi, Şanlıurfa Mehmet Akif İnan Eğitim ve Araştırma Hastanesi, Kalp ve Damar Cerrahisi Kliniği, 63330 Karaköprü, Şanlıurfa, Turkey. Tel: +90414-3186000 e-mail: mesut_kvc_cor@hotmail.com 
options depend on etiology, location of the aneurysm, and symptoms. Extracranial ICA aneurysm surgery may be performed with ultrasonography and conventional angiography findings. ${ }^{[3]}$ Arteriovenous malformations are also associated with high risk of mortality. Arterial aneurysms and cerebral AVMs may coexist and are classified among themselves. ${ }^{[4]}$ We present this case to illustrate unexpected fatal complications that may occur after carotid artery aneurysm surgery. Surgery of carotid artery aneurysm must be carefully planned to avoid unexpected postoperative outcomes.

\section{Declaration of conflicting interests}

The authors declared no conflicts of interest with respect to the authorship and/or publication of this article.

\section{Funding}

The authors received no financial support for the research and/or authorship of this article.

\section{REFERENCES}

1. Sokullu O, Şerbetçioğlu A, Sanioğlu S, Kurç E, Enç Y, Bilgen F. Extracranial carotid artery aneurysms: two case reports. Turk Gogus Kalp Dama 2002;10:181-3.

2. Shimada T, Toyoda K, Hagiwara N, Sayama T, Inoue T, Yasumori K, et al. Recurrent embolic stroke originating from an internal carotid aneurysm in a young adult. J Neurol Sci 2005;232:115-7.

3. Sasmazel A, Celik C, Ersoy C, Akcevin A. Surgical treatment of an extracranial carotid artery aneurysm: a case report. Arch Turk Soc Cardiol 2005;33:291-3.

4. Redekop G, TerBrugge K, Montanera W, Willinsky R. Arterial aneurysms associated with cerebral arteriovenous malformations: classification, incidence, and risk of hemorrhage. J Neurosurg 1998;89:539-46. 